\title{
Activity descriptors derived from comparison of Mo and Fe as active metal for methane conversion to aromatics
}

\author{
Ina Vollmer ${ }^{\mathrm{a}}$, Samy Ould-Chikh ${ }^{\mathrm{b}}$, Antonio Aguilar-Tapiac, Guanna Li ${ }^{\mathrm{a}, \mathrm{d}}$, Evgeny Pidko ${ }^{\mathrm{d}}$, Jean-Louis Hazemann ${ }^{\mathrm{c}}$, \\ Freek Kapteijn ${ }^{\mathrm{a}}$ and Jorge Gascon ${ }^{\mathrm{b}, *}$
}
${ }^{a}$ Catalysis Engineering, Department Chemical Engineering, Delft University of Technology, Delft, The Netherlands
b Advanced Catalytic Materials, KAUST Catalysis Center, King Abdullah University of Science and Technology, Thuwal, Saudi Arabia
${ }^{\mathrm{c}}$ Inst. Neel, UPR 2940 CNRS - Univ. Grenoble Alpes, F-380oo Grenoble, France
${ }^{d}$ Inorganic Systems Engineering, Department Chemical Engineering, Delft University of Technology, Delft, The
Netherlands

KEYWORDS. Methane dehydroaromatization, HZSM-5, Mo/HZSM-5, Fe/HZSM-, Molybdenum (Mo), Iron (Fe), Transition metal ion, X-ray absorption spectroscopy, Multivariate Curve Resolution Analysis (MCR-ALS), TEM, nanoparticle.

\begin{abstract}
Producing aromatics directly from the smallest hydrocarbon building block, methane, is attractive because it could help satisfy increasing demand for aromatics while filling the gap created by decreased production from naphtha crackers. The system that catalyzes the direct methane dehydroaromatization (MDA) best so far is Mo supported on zeolite. Mo has shown to outperform other transition metals (TMs). Here we attempt to explain the superiority of Mo by directly comparing Fe and Mo supported on HZSM- 5 zeolite. To determine the most important parameters responsible for the superior performance of Mo, detailed characterization using X-ray absorption spectroscopy (XAS) techniques combined with catalytic testing and theoretical calculations are performed. The higher abundance of mono- and dimeric sites for the Mo system, their ease of carburization in methane as well as intrinsically lower activation energy barriers of breaking the methane $\mathrm{C}-\mathrm{H}$ bond over Mo explain the better catalytic performance. In addition, a pretreatment in $\mathrm{CO}$ is presented to more easily carburize Fe and thereby improve its catalytic performance.
\end{abstract}

\section{Introduction}

Much research effort focusses on the direct conversion of methane, i.e. via oxidation to methanol (MTM) or oxidative coupling, because of the high availability of methane in shale gas, from coalbeds and clathrates..$^{1-2}$ The direct conversion of methane to aromatics without the addition of oxidants has the potential additional benefit of producing aromatics, much desired for the production of polystyrene and numerous consumer goods. The methane dehydroaromatization (MDA) reaction is however limited by thermodynamics and has to be run at high temperatures around $700{ }^{\circ} \mathrm{C}$ to achieve around $12 \mathrm{~mol} \%$ conversion of methane to benzene and hydrogen. Although this thermodynamic limit is almost reached using a catalyst, where Mo is supported on HZSM-5 zeolite, mainly its insufficient stability has hampered the development of an industrial process. The main challenge is the fast deposition of bulky aromatics that block the catalytic sites thereby deactivating them. A catalyst that is more stable and selective to aromatics like benzene is desired.

Breaking the stable $\mathrm{C}-\mathrm{H}$ bond in methane requires a very active catalyst. While several transition metal ions (TMI) supported on zeolite have been shown to catalyze MDA, Mo has continued to lead to the highest activity and selectivity to benzene and napthalene. ${ }^{3-13}$ Mo can form monomeric ${ }^{14}$ species as shown by UV Raman and likely also dimeric species ${ }^{15}$ that are stabilized in the pores of the zeolite by anchoring to framework Al through oxygen bridges, balancing the charge introduced by replacing the tetravalent $\mathrm{Si}$ of the zeolite framework with trivalent $\mathrm{Al}$ (Scheme Si). While these mono- or dimeric species define the activity of the catalyst, the presence of bigger Mo clusters on the outer surface of the zeolite is hard to avoid. ${ }^{16}$ The mono- or dimeric Mo species are assumed to contribute most to catalytic activity, while bigger nanoparticles of Mo on the outer surface of the zeolite were found to speed-up the deactivation of the catalyst through coking. ${ }^{16}$

Using $\mathrm{Fe} / \mathrm{HZSM}-5$ as MDA catalyst, a lower methane conversion (3-4.1 mol\%) and lower naphthalene and benzene formation rates than over Mo/HZSM-5 were observed, but no explanation provided.3, ${ }^{17} \mathrm{Fe}$ supported on zeolites is a wellstudied catalyst for the deNOx reaction and was also studied for the MTM reaction. ${ }^{18-30}$ Similar to Mo, Fe anchors to the framework $\mathrm{Al}$ as mono- or dimeric species, but most of the $\mathrm{Fe}$ is present as bigger clusters unless a complicated synthesis method is applied. ${ }^{26,}{ }^{28} \mathrm{As}$ for Mo, bigger clusters of Fe are detrimental for the catalytic performance. $3^{1}$ 
In the presence of $\mathrm{CH}_{4}$, Mo transforms to (oxy-) carbidic species.3, 13, 32-33 This transformation marks the 'activation period' of the catalyst as benzene is only produced after Mo (oxy-)carbides are formed (Scheme 1).34-35 We found that this activation can also be achieved with a pre-treatment under $\mathrm{CO}$ atmosphere, which leads to an equivalent active phase of Mo. ${ }^{6}$ During this treatment, no carbonaceous deposits are formed as would during activation in $\mathrm{CH}_{4}$. The activation period is followed by the induction period, during which the formation rate of gaseous products slowly increases. This slow increase is related to the necessary buildup of active hydrocarbon pool species inside the pores of the catalyst.34 Finally, after completion of the activation and induction period, benzene, naphthalene, ethylene, ethane and toluene are formed in the gas-phase concurrent with continuous deposition of deactivating carbonaceous deposits that block the active sites and the pores of the zeolite.

Scheme 1. Illustration of the different phases of the methane dehydroaromatization reaction.

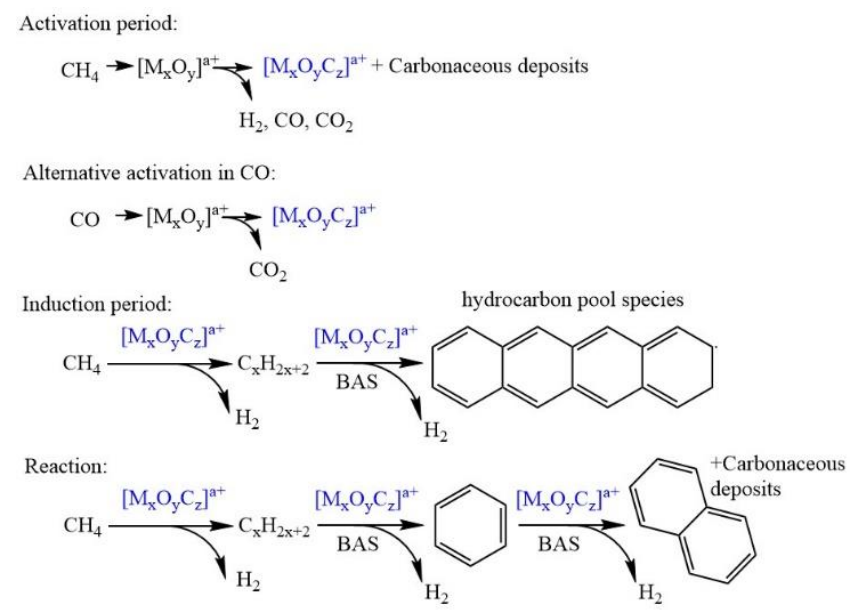

Mo carbide is suggested to have a unique electronic structure, which is similar to that of noble metals. Mo carbide was observed to behave similarly to precious metals in other reactions. During an initial activation period, Fe also reduces, which takes longer than for Mo.3, 17,32 There is however significant disagreement on the exact make-up of the active phase and XPS results suggest that the active phase contains very little carbidic character, contrary to what was found for Mo. ${ }^{17}$ This difference could determine the catalytic performance, because the carbidic carbon itself can play a role in activating methane equivalent to oxygen in the Mars-Van-Krevelen mechanism 37 as was recently found by the authors. Carbon from the active site was found to be incorporated into the final products. ${ }^{6}$ A similar observation was made for iron carbides in the Fischer-Tropsch synthesis, where iron carbide initiates the hydrocarbon chain growth.38-39 For FischerTropsch, both DFT studies and experimental work suggest that $\mathrm{CH}_{2}$ fragments can easily be formed by reaction of the carbon from the active site with gas phase hydrogen. $4^{\circ}$

X-ray absorption spectroscopy (XAS) is a very powerful technique to study the transformation of TMIs under harsh reaction atmosphere and was used to study Mo/HZSM-5 and its activation under MDA conditions operando.34, 36, 41-43 XAS directly probes the state of the TMI, with the singular advantage of XANES spectroscopy which is barely influenced by the elevated temperature of the MDA reaction. Since signals are averaged, XAS as a bulk technique has some limitations. Especially when the TMI is present both as monoand dimeric species as well as in clusters, as in the case of Fe/ZSM- 5 and $\mathrm{Mo} / \mathrm{HZSM}_{-} 5$, it is difficult to interpret the spectra. In addition, several phases of Fe in different oxidation states and as (oxy-) carbides co-exist at reaction conditions complicating the analysis further. Multivariate curve resolution (MCR) analysis is used for decomposition of the measured X-ray absorption near edge spectra (XANES), that represent an average over all absorbing atoms, into the individual spectra of the different phases present. ${ }^{44-46}$ Herewith, the fractional contribution of each phase can be determined.

This paper aims at understanding the differences in activity of $\mathrm{Mo} / \mathrm{HZSM}_{-5}$ and $\mathrm{Fe} / \mathrm{HZSM}_{-5} 5$ building on previous results obtained for Mo/HZSM-5. To the best of our knowledge operando information on the development of the active site of Fe/HZSM- 5 during MDA is lacking. Therefore, the activation of Fe and the makeup of the Fe active phase are studied and compared with $\mathrm{Mo} / \mathrm{HZSM}-5$ using operando XAS measurements during different reaction treatments that resemble the experiments the authors previously performed on Mo/HZSM-5.35-36 The results are directly compared to observations made on Mo and differences are linked to the aromatics and coke selectivities and yields of the two catalysts. Experimental results are further explained using theoretical calculations. $\mathrm{C}-\mathrm{H}$ activation over several structures of mono- and dimeric (oxy-)carbidic Mo and Fe species anchored to the zeolite as well as over carbidic and metallic surfaces are performed to determine which structures of Mo and Fe are most stable and which ones are most active. Density functional theory (DFT) calculations can give more insight into which configurations of Mo or Fe are most active for MDA as was done for fully carbidic Mo clusters. 47 Activation barriers over the same structures with $\mathrm{Fe}$ and Mo are compared to understand the lower methane conversion observed over Fe/HZSM-5.

\section{Methods}

\subsection{Catalyst synthesis}

Commercial H-ZSM-5 (PQCorporation, CBV 502oE, $\mathrm{Si} / \mathrm{Al}=24$ ) was loaded with $2 \mathrm{wt}$. $\%$ of Fe or $3.37 \mathrm{wt}$.\% of Mo, corresponding to a molar TMI/Al ratio of 0.6 using incipient wetness impregnation (IWI). The impregnation solution contained for $\mathrm{Fe} / \mathrm{HZSM}-5$ iron(III) nitrate hydrate $\left(\mathrm{Fe}\left(\mathrm{NO}_{3}\right)_{3} \bullet_{9} \mathrm{H}_{2} \mathrm{O}\right)$ and for Mo/HZSM-5 ammonium heptamolybdate $\left(\left(\mathrm{NH}_{4}\right)_{6} \mathrm{Mo}_{7} \mathrm{O}_{24}\right.$, AHM) dissolved in a volume of water needed to fill the pores of the zeolite powder $(400$ $\mu \mathrm{l} / \mathrm{g}$ ). The zeolite supports were dried overnight at $120^{\circ} \mathrm{C}$ before impregnation. The impregnation solution was added dropwise to a to the dried zeolite in a mortar under constant agitation. After impregnation, samples were dried at $80^{\circ} \mathrm{C}$ for $12 \mathrm{~h}$ and subsequently calcined at $550^{\circ} \mathrm{C}$ in static air for 5 h using a heating rate of $2{ }^{\circ} \mathrm{C} / \mathrm{min}$.

\subsection{Catalytic testing}

Catalytic testing was performed in a quartz reactor tube with an inner diameter of $6 \mathrm{~mm}$, using $500 \mathrm{mg}$ catalyst pelletized to pellets of 212 to $355 \mu \mathrm{m}$. A weight hourly space velocity (WHSV) of $1.21 \mathrm{~h}^{-1}$ (based only on methane flow) and a reaction temperature of $700{ }^{\circ} \mathrm{C}$ was applied in all tests. Product analysis was achieved on an Interscience Trace GC with a TCD and two FIDs. A mixture $5 \% \mathrm{~N}_{2}$ in $\mathrm{CH}_{4}$ was fed to 
the reactor, where $\mathrm{N}_{2}$ was used as an internal standard according to Equation 1, where $A_{i, i n}\left(i=\mathrm{CH}_{4}\right.$ or $\left.\mathrm{N}_{2}\right)$, the integrated peak area from the GC analysis is determined from three initial GC calibration injections before increasing the temperature for each run. The reactor was brought to reaction temperature under the same flow with a heating rate of $10^{\circ} \mathrm{C} / \mathrm{min}$. Product yields were calculated according to Equation 2, selectivity to each gaseous product at each GC injection according to Equation 3 and selectivity to each gaseous product over the whole time on stream (TOS) according to Equation 4. Coke selectivity over the whole TOS calculated with Equation 5.

$$
\begin{aligned}
& X_{C_{4}}=\frac{\left(\frac{{ }_{C H_{4}, \text { in }}}{A_{N_{2}, \text { in }}}\right)-\left(\frac{{ }^{A}{ }_{C H_{4}, \text { out }}}{A_{N_{2}, \text { out }}}\right)}{\frac{{ }_{C} \mathrm{CH}_{4}, \text { in }}{{ }_{N_{2}, \text { in }}}} * 100 \% \\
& Y_{\text {product }}[\mathrm{mol} \%]=\frac{F_{C_{i} H_{j}}}{F_{C_{4}, \text { in }}} * i * 100 \% \\
& S_{\text {product }}[\text { mol\% }]=\left(\frac{Y_{\text {product }}}{X_{\mathrm{CH}_{4}}}\right)_{\text {injection, } i} \\
& \sum_{\text {Tos }} S_{\text {product }}[\text { mol\% }]=t_{\text {injection }} \sum_{i} \frac{Y_{\text {product }}}{X_{\mathrm{CH}_{4}}} \\
& \sum_{\text {TOS }} S_{\text {coke }}[\mathrm{mol} \%]=\sum_{\text {TOS }} X_{\mathrm{CH}_{4}}-\sum_{\text {TOS }} S_{\text {product }}
\end{aligned}
$$

CO carburization was performed on a custom-made setup, where a $30 \mathrm{ml} / \mathrm{min}$ flow of $2.5 \% \mathrm{CO}$ in He was continuously fed to the reactor containing $300 \mathrm{mg}$ catalyst, pelletized and sieved to 212 to $355 \mu \mathrm{m}$ particles. The reactor consists of a quartz tube with an inner diameter of $6 \mathrm{~mm}$. A heating rate of $10{ }^{\circ} \mathrm{C} / \mathrm{min}$ to $780{ }^{\circ} \mathrm{C}$ (if not otherwise stated) was applied and the reactor was kept at the final temperature for $1 \mathrm{~h}$.

\subsection{Multivariate curve resolution (MCR) analysis}

Multivariate curve resolution (MCR) is a chemometric technique, allowing to deconvolute a data set $D$ made up of $q$ measured spectra, which represent a mixture of $N(N<q)$ pure spectra comprised in matrix $S$. These spectra are found numerically solving $D=C S^{T}-E$, where $S^{T}$ is the transpose of matrix $S, E$ comprises the errors arising from the reconstruction and $C$ is a matrix containing the concentration of the pure spectra $N$ in each measured spectrum $q$. An alternating least squares (ALS) algorithm is employed as implemented in the MCR-ALS graphical user interface (GUI) by Jaumot and coworkers, ${ }^{4}$ freely downloadable at http://www.mcrals.info/(accessed December 2018) for Matlab R2onb. To achieve the resolution of the multivariate dataset $D$, first the number of statistically significant pure components $N$ has to be found. This is achieved by using singular value decomposition (SVD) as detailed in the appendix (section S8). To get a statistically more meaningful result, operando XANES spectra corresponding to 9 different experimental conditions were appended column-wise to obtain dataset $D$, totaling 378 XANES spectra. The following soft constraints were used for the ALS routine: nonnegativity for both pure spectra and concentration profiles (using the fast non-negative least-squares algorithm) and closure to 1 for the concentration profiles (justified, because XAS is an element-selective technique, probing all $\mathrm{Fe}$ in the system). The optimization routine successfully converged after 8 iterations with acceptable ALS quality control parameters (Table $\mathbf{S}_{3}$ ).

\subsection{DFT calculations}

Periodic DFT calculations were performed to determine the activation barrier of methane $\mathrm{C}-\mathrm{H}$ bond breaking over mono- and dimeric Mo and Fe molecular species in different speciation as well as over carbide surfaces.

\subsubsection{Structural models}

Extra-framework $\left[\mathrm{M}_{\mathrm{x}} \mathrm{O}_{\mathrm{y}} \mathrm{C}_{\mathrm{z}}\right]^{\alpha+}(x, \mathrm{z}=1$ or $2, \mathrm{y}=\mathrm{o}$ or $1, \alpha=$ 1 or 2) clusters were constructed in the ZSM-5 zeolite framework as counter-ion for two $(\alpha=2)$ and one $(\alpha=1)$ framework $\mathrm{Al}\left(\mathrm{F}_{\mathrm{Al}}\right)$ ion (Figure 5 and Figure $\left.\mathbf{S}_{34-35}\right)$. The $\mathrm{F}_{\mathrm{Al}}$ anchoring sites for the carbide structures are positioned in the six-membered ring located in the straight channel, previously referred to as $\delta$-site or in the sinusoidal channel $(\beta$-site) as well as in the eight-membered ring at the intersection of the straight and zig-zag channel ( $\gamma$-site) (Figure S33).49 The Tsite locations of $\mathrm{F}_{\mathrm{Al}}$ are summarized in Table $\mathbf{S}_{7}$. Gao et al. calculated the Raman frequency for a monomeric oxide structure in this location and confirmed that it falls within the experimentally observed range. ${ }^{14}$ Analysis in the more confined $\gamma$-site was added to account for the effect of Vander-Waals forces on the activation barriers. The three different sites investigated here were found to be typical locations for framework $\mathrm{Al}$, with the $\beta$-site being the most prominent.50-51Thermodynamic analysis showed that The resulting ZSM- 5 model had a $\mathrm{Si} / \mathrm{Al}$ ratio of 47 for an $\mathrm{Al}$-pair and 94 for single Al. One unit cell of the ZSM- 5 was considered $\left(\mathrm{Si}_{96} \mathrm{O}_{192}\right)$.

Carbide and metal phases that would match the measured XANES spectra were constructed and their most stable surfaces considered for calculating the activation energy barriers for the $\mathrm{H}$-abstraction from methane. For Fe, the (o10) surface of $\mathrm{Fe}_{5} \mathrm{C}_{2}{ }^{2}$, the (oo1) surfaces of $\mathrm{Fe}_{3} \mathrm{C}_{53}, \alpha$-Fe and $\gamma$-Fe are considered. For Mo, the (o11) surface of $\beta-\mathrm{Mo}_{2} \mathrm{C}$ is considered.54-55 More details on the slab model construction can be found in the SI (Table S1o, Figure S38). For the geometry optimizations only the atoms of the top layer of the surface model were allowed to relax.

\subsubsection{Computational details}

All spin polarized DFT calculations were performed by using the Vienna Ab initio Simulation Package (VASP, version 5.3.5).56-59 The PBE functional based on the generalized gradient approximation was chosen to account for the exchange-correlation energy. ${ }^{60}$ A plane-wave basis set in combination with the projector augmented wave (PAW) method was used to describe the valence electrons and the valencecore interactions, respectively. ${ }^{61-62}$ The kinetic energy cut-off of the plane wave basis set was set to $500 \mathrm{eV}$. A Gaussian smearing of the population of partial occupancies with a width of $0.05 \mathrm{eV}$ was used during iterative diagonalization of the Kohn-Sham Hamiltonian. Considering the large unit cell, Brillouin zone-sampling was restricted to the $\Gamma$ point for the zeolite related models. The details for Brillouin sampling for the metal and carbide surfaces can be found in the SI. ${ }^{6} \mathrm{Ge}-$ ometry optimizations were assumed to have converged when forces on each atom were less than $0.05 \mathrm{eV} / \AA$. The van der Waals (vdW) interactions were included by using Grimme's $\mathrm{DFT}_{3} \mathrm{D}_{3}(\mathrm{BJ})$ method as implemented in VASP. ${ }^{4}$ The nudgedelastic band method with the improved tangent estimate (CI$\mathrm{NEB})^{65}$ was used to determine the minimum energy path and to locate the transition state structure for each elementary reaction step. The maximum energy geometry along the reaction path generated by the CI-NEB method was further optimized using a quasi-Newton algorithm. In this procedure, only the extra-framework atoms and the surface spe- 
cies were relaxed. Transition state was confirmed by showing a single imaginary frequency corresponding to each reaction coordinate.

\section{Results}

\subsection{Catalytic performance}

For a fair comparison, the same molar amount of Fe and Mo (Table Si) rather than the same weight loading were introduced to a commercial zeolite (PQCorporation, CBV $5020 \mathrm{E}, \mathrm{Si} / \mathrm{Al}=24)$ using incipient wetness impregnation (IWI). Methane conversion as well as naphthalene and benzene yields are lower for $\mathrm{Fe} / \mathrm{HZSM}_{-5} 5$ than for $\mathrm{Mo} / \mathrm{HZSM}-5$. There are also differences in the reaction profiles.

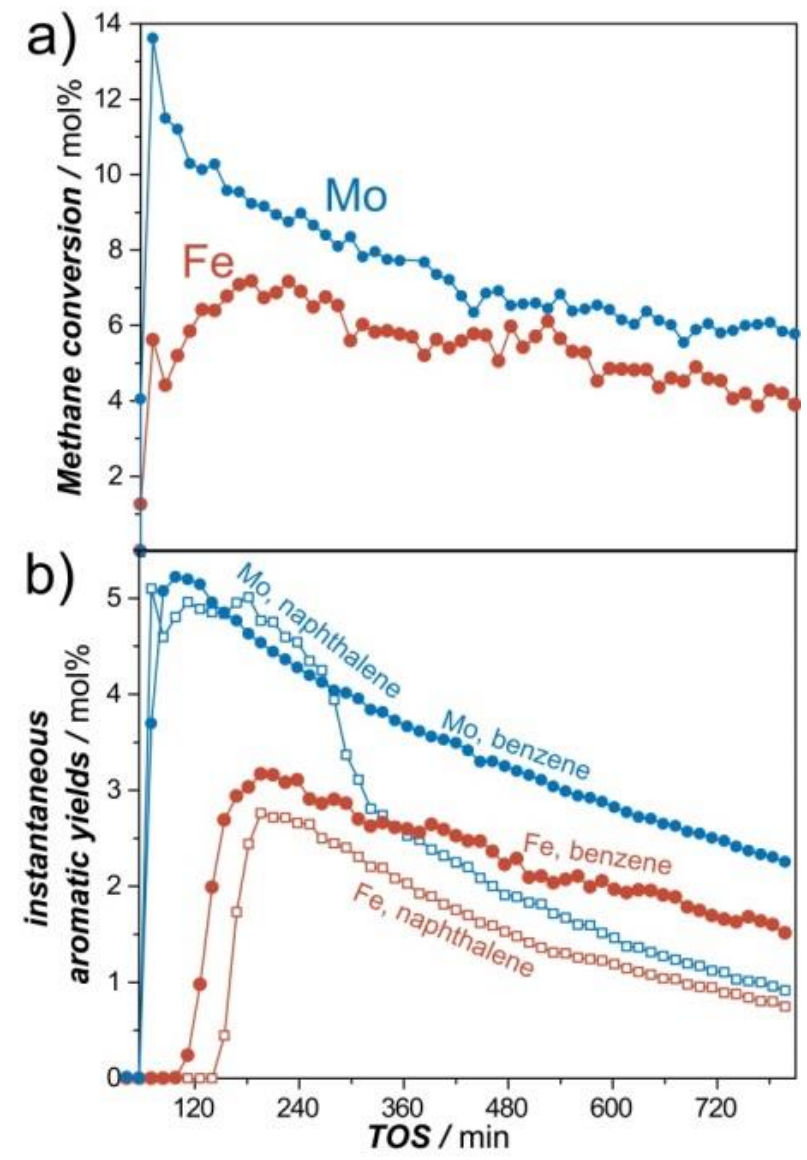

Figure 1. a) Methane conversion and b) yields to naphthalene and benzene as a function of time on stream (TOS) when feeding $15 \mathrm{ml} / \mathrm{min} 5 \mathrm{~mol} \% \mathrm{~N}_{2} / 95 \mathrm{~mol}_{\%} \mathrm{CH}_{4}$ to $500 \mathrm{mg}$ of catalyst (either $\mathrm{Fe} / \mathrm{HZSM}-5$ or $\mathrm{Mo} / \mathrm{HZSM}-5$ ) at $700{ }^{\circ} \mathrm{C}$. See Figures $\mathrm{S}_{1-3}$ for yields to $\mathrm{CO}$, toluene, ethylene and ethane.

For $\mathrm{Fe} / \mathrm{HZSM}-5$, the methane conversion gradually increases with TOS while the activation and induction period take place (Scheme 1) and the activation period, evident from the delay in aromatics production, takes much longer over Fe/HZSM- 5 than over the Mo catalyst. Over Mo/HZSM5, methane conversion and aromatics production start promptly indicating a faster activation and induction period. Interestingly, ethylene and ethane form in very low amounts already before the onset of aromatics formation over Fe/HZSM-5 (Figure $\mathbf{S}_{3}$ ). Fe/HZSM-5 is much more prone to coking as the integral selectivity to coke is twice as high for Fe than for Mo (Table S2).

\subsection{Catalyst activation}

Denerdin et al. showed that the reducibility of the TM is related to MDA performance. ${ }^{66}$ To understand the reduction and carburization process of Fe and Mo better, the carburization dynamics under methane atmosphere are compared with carburization under $\mathrm{CO}$ atmosphere. The temperature at which reduction starts is determined by temperature programmed reduction (TPR) experiments. Flowing either carbon monoxide or methane over the catalyst, the temperature is ramped to $780{ }^{\circ} \mathrm{C}$ at $10{ }^{\circ} \mathrm{C} / \mathrm{min}$. An equivalent active phase is formed with the two treatments as is demonstrated by the immediate activity to form benzene demonstrated by the CO-treated catalyst (Figure $\mathbf{S}_{\mathbf{5}}$ ). In addition, the XANES spectra measured after the CO-treatment and on the methane activated sample match except for a slight difference of the pre-edge feature (Figure S1o).

The reduction kinetics with the two gases $\mathrm{CO}$ and $\mathrm{CH}_{4}$, however, are very different. When using methane, carbon monoxide starts to evolve already at lower temperatures for Mo than for Fe (

Figure 2). This indicates that conditions necessary to reduce Mo with methane are milder than for Fe. The opposite trend is observed during CO-TPR. The removal of oxygen evident from $\mathrm{CO}_{2}$ formation starts at lower temperatures for Fe $\left({ }^{\sim} 230^{\circ} \mathrm{C}\right)$ than for $\mathrm{Mo}\left({ }^{\sim} 430^{\circ} \mathrm{C}\right)$.

These results are compared with thermodynamic calculations for the reduction of bulk oxides to bulk carbides (Figure S11-12). Both reduction by $\mathrm{CO}$ as well as by $\mathrm{CH}_{4}$ is thermodynamically more favorable for Mo than for Fe. The easier reduction of $\mathrm{Fe} / \mathrm{HZSM}_{-} 5$ with $\mathrm{CO}$, observed experimentally should thus be due to favored reduction kinetics rather than thermodynamic control.

The activation of Fe/HZSM-5 is not only easier with $\mathrm{CO}$, it also creates a more active catalyst that shows a higher methane conversion and higher yields to benzene and naphthalene than after methane activation (section $\mathbf{S}_{\mathbf{3}}$ ). Conversely, this positive effect of the CO-treatment is not observed for Mo/HZSM-5, which reduces at higher temperatures with $\mathrm{CO}$ than with $\mathrm{CH}_{4}$. Thus, carburizability also relates to catalytic activity and partly explains the lower performance of $\mathrm{Fe}$ compared to Mo in MDA: The higher the carburization activity of the TMI/carburization gas combination, the higher the activity of the active phase created during the reduction treatment. It should be noted that the higher temperature needed for the CO-treatment also decreases the acidity of Mo/HZSM- 5 and thus lowers the performance of Mo/HZSM5 treated this way. ${ }^{34}$

Another explanation for the improved performance of Fe/HZSM- 5 after $\mathrm{CO}$ activation is due to a side effect associated with $\mathrm{CH}_{4}$ carburization of TMs. Instead of selectively reducing the $\mathrm{TM}$, methane also reacts to form immobile aromatic compounds that lead to pore blockage and catalyst deactivation. This is evident from the high production of hydrogen already during this period which was previously shown for Mo. 35 This aromatics formation during the activation period can be avoided with a CO-treatment as no deactivating species are formed in that case. ${ }^{6}$ Generally, the shorter the activation necessary under methane atmosphere, the more active the catalyst. 

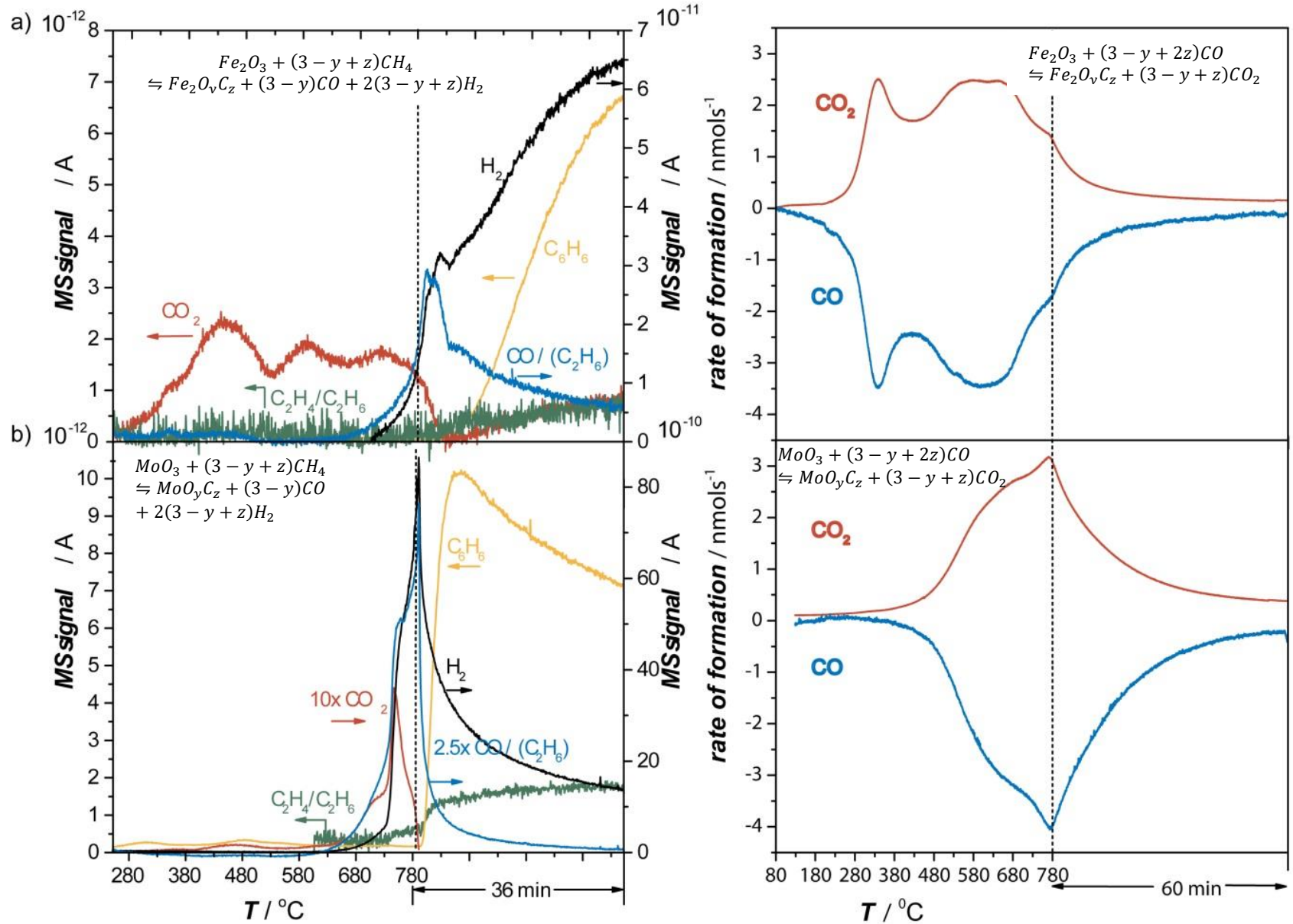

Figure 2. Left: $\mathrm{MS}$ signals of $\mathrm{H}_{2}, \mathrm{CO}, \mathrm{CO}_{2}, \mathrm{C}_{2} \mathrm{H}_{4} / \mathrm{C}_{2} \mathrm{H}_{6}$ and $\mathrm{C}_{6} \mathrm{H}_{6}(\mathrm{~m} / \mathrm{z}=2,28,44,27,78)$ measured during $\mathrm{CH}_{4}-\mathrm{TPR}$ over

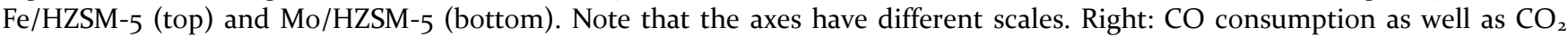
production during CO-TPR over Fe/HZSM-5 (top) and Mo/HZSM-5 (bottom). Reduction by oxygen removal is indicated by CO evolution during $\mathrm{CH}_{4}$-TPR and $\mathrm{CO}_{2}$ evolution during $\mathrm{CO}$-TPR. It has to be noted that $\mathrm{CO}_{2}$ production during $\mathrm{CH}_{4}$-TPR is by a factor of 10 lower than $\mathrm{CO}$ production and therefore $\mathrm{CO}$ production is taken as the main indication of oxygen removal.

\subsection{Structural characterization}

For Mo/HZSM-5 it is well known that the oxidic catalyst precursor undergoes reduction and carburization at reaction conditions and can only activate the reaction of methane to benzene and naphthalene after completing this so called 'activation period'. ${ }^{6,4}, 41,67-72,73$ It was suggested that Fe also has to undergo such a carburization to develop its activity. ${ }^{32}$ To verify this and to better understand the final structure of the Fe active site, operando XANES was performed and the data analyzed by multivariate curve resolution (MCR) analysis.

Operando XANES spectra were collected while subjecting the catalyst to several reaction treatments (Figure 3). Before introducing methane to the catalyst, the temperature was ramped to the reaction temperature of $700{ }^{\circ} \mathrm{C}$ under He, which is referred to as He-treatment. Once the reaction temperature is reached, pulses of methane are sent to the catalyst until full activation is reached, evident from the evolution of benzene. This pulse-reaction technique34, 68 (see Figure $\mathrm{S}_{13}$ for illustration) was employed, which is a very controlled way to conduct the reaction. A XANES spectrum can be measured after every pulse of methane sent to the catalyst and the evolution of product gasses is monitored at the same time by online mass-spectrometry. This allows capturing the transformation of the as-synthesized iron phase to its active phase with enough detail to determine the phase responsible for benzene formation. In addition, as previous experiments on $\mathrm{Mo} / \mathrm{HZSM}_{-} 5$ were performed the same way, direct comparison is possible. ${ }^{6}$

Once maximum benzene levels were reached, a continuous flow of methane was sent to the catalyst until deactivation occurred. Alternatively, temperature programmed reaction was performed flowing diluted methane $\left(\mathrm{CH}_{4}-\mathrm{TPR}\right)$, carbon monoxide (CO-treatment) or hydrogen $\left(\mathrm{H}_{2}\right.$-treatment). In the TPR experiments, the catalyst was first heated to $200{ }^{\circ} \mathrm{C}$ and kept there until all adsorbed water had evolved from the catalyst. Afterwards, the flow was switched to the gas-mixture and temperature further increased to $780{ }^{\circ} \mathrm{C}$. Methane pulsing was also performed following the $\mathrm{CO}$ - and the $\mathrm{H}_{2}$-treatment.

In Figure 3 the XANES spectra collected every $\sim 3$ min are shown with colors going from dark blue via turquoise to brown. The treatments generally lead to an increase in the pre-edge feature, a decrease in the post-edge feature, a flattening of the post-edge features in general and a shift of the edge position to a lower energy. The reduction during the $\mathrm{CO}$ - and the $\mathrm{H}_{2}$-treatment goes via an intermediate state at $\sim 500{ }^{\circ} \mathrm{C}$, which is characterized by a sudden rise in the postedge feature. 


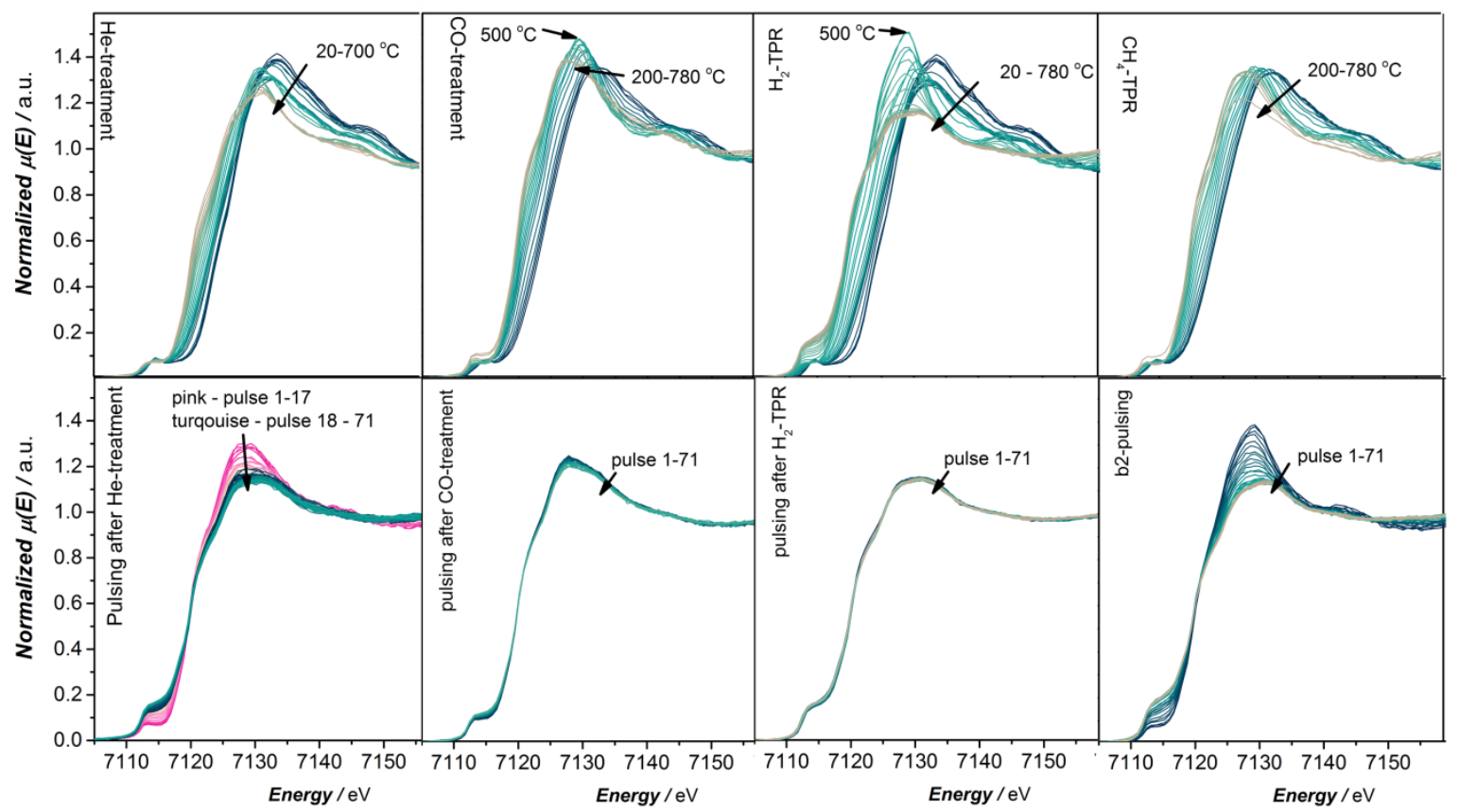

Figure 3. Operando Fe K-edge XANES spectra collected while subjecting Fe/HZSM-5 to several reaction treatments. Before introducing methane to the catalyst, the temperature was ramped to the reaction temperature of $700{ }^{\circ} \mathrm{C}$ under He, which is referred to as He-treatment. Once the reaction temperature is reached, pulses of methane are sent to the catalyst until full activation is reached (pink spectra). After CO-treatment the catalyst is immediately active to form benzene. As similar phase is formed during $\mathrm{H}_{2}$-treatment as during CO-treatment, pulsing methane and $\mathrm{CH}_{4}$-TPR, but the catalyst is not immediately active to form benzene after $\mathrm{H}_{2}$-treatment. b2-pulsing denotes the pulse-reaction performed over a He-treatment catalyst that was synthesized with bigger particles of Fe (see section S9).

In a first attempt to assign the structure of the active phase, a spectrum recorded right before the onset of benzene formation is compared to known carbidic compounds (Figure S16). However, visual inspection or linear combination fitting of the XANES finger-print region proved inconclusive (Figure S17). To determine the exact nature of the active Fe species is difficult, because the structure Fe takes on the support is different from a bulk iron carbide.

Rather, Fe forms small cluster species inside the pores of the zeolite that are anchored by the framework Al. This can be inferred from the decrease of BAS shown by Py IR ${ }^{26}, 28$ (Figure S18), because Fe cations replace the acidic proton of the BAS when anchoring to framework Al. In addition, Fe nanoparticles on the outer surface of the zeolite crystal are also present as determined by TEM (Figure S19-21). Further complicating the picture, a mixture of Fe species with varying degree of reduction and carburization is formed after exposure of the catalyst to reaction atmosphere. Thus, the measured spectra represent a mixture of spectra of pure components. PCA and MCR-ALS were used next to find the pure components comprising the measured spectra. To reliably detect all the components, PCA was performed on all XANES spectra recorded operando during the reaction treatments described above. It was found that a minimum of four components can reasonably fit all 378 spectra (Figure S22). The MCR alternating least squares (MCR-ALS) routine yields each spectrum associated to those four pure Fe species (Figure S23). Comparing the theoretical spectra of the four components to spectra of reference compounds and with knowledge of the corresponding process conditions, their identity can be refined. $\mathrm{PC}_{1}$ corresponds to the initial state of the catalyst, as the theoretical spectrum of $\mathrm{PC}_{1}$ and the spectrum taken of the catalyst prior to any treatment are very similar (Figure S23). Prior to any treatment, $\mathrm{Fe}$ is in a mixture of hematite $\left(\mathrm{Fe}(\mathrm{III}), \alpha-\mathrm{Fe}_{2} \mathrm{O}_{3}\right)$ and magnetite (Fe(II,III), $\mathrm{Fe}_{3} \mathrm{O}_{4}$ ) as was also observed before ${ }^{26,28}$. Upon heating in He, the catalyst reduces until it is mainly made up of $\mathrm{PC}_{2}$, which closely resembles wüstite (Fe(II), FeO). $\mathrm{PC}_{2}$ also forms during $\mathrm{CH}_{4}$-TPR and CO-TPR while it is most dominant during the $\mathrm{H}_{2}-\mathrm{TPR}$ at $470{ }^{\circ} \mathrm{C} . \mathrm{PC}_{3}$ and $\mathrm{PC}_{4}$ start to appear right after $\mathrm{PC}_{2}$ reaches its maximum concentration for all experimental conditions. The identity of $\mathrm{PC}_{4}$ species could not be identified by simple comparison with references, but judging from the edge-position it seems to be another $\mathrm{Fe}(\mathrm{II})$ species. $\mathrm{PC}_{3}$ dominates the spectrum after the $17^{\text {th }}$ pulse of methane has been sent to the reactor. At this point benzene slowly starts forming (Figure S13-14). After benzene starts evolving, the catalyst slightly reduces further, but reaches a stable level soon after (Figure 4). The approach to the final state of reduction is reached much faster than the maximum benzene formation level (Figure S25). The increase in benzene formation and the increase in the fraction of $\mathrm{PC}_{3}$ are not directly related, however benzene only forms after $\mathrm{PC}_{3}$ has been formed. $\mathrm{PC}_{3}$ is thus assigned as the main active phase. Although the XANES spectrum of $\mathrm{PC}_{3}$ is typical of a reduced form of iron, it does not match any of the measured reference compounds $\left(\mathrm{Fe}_{3} \mathrm{C}, \mathrm{Fe}_{2} \mathrm{C}_{5}\right.$ or $\mathrm{Fe}$ foil). The phase corresponding to $\mathrm{PC}_{3}$ is tentatively assigned to a reduced/metallic iron phase that can include various amount of oxycarbidic carbon $\left(e g . \mathrm{FeO}_{\mathrm{x}} \mathrm{C}_{\mathrm{y}}\right)$. 

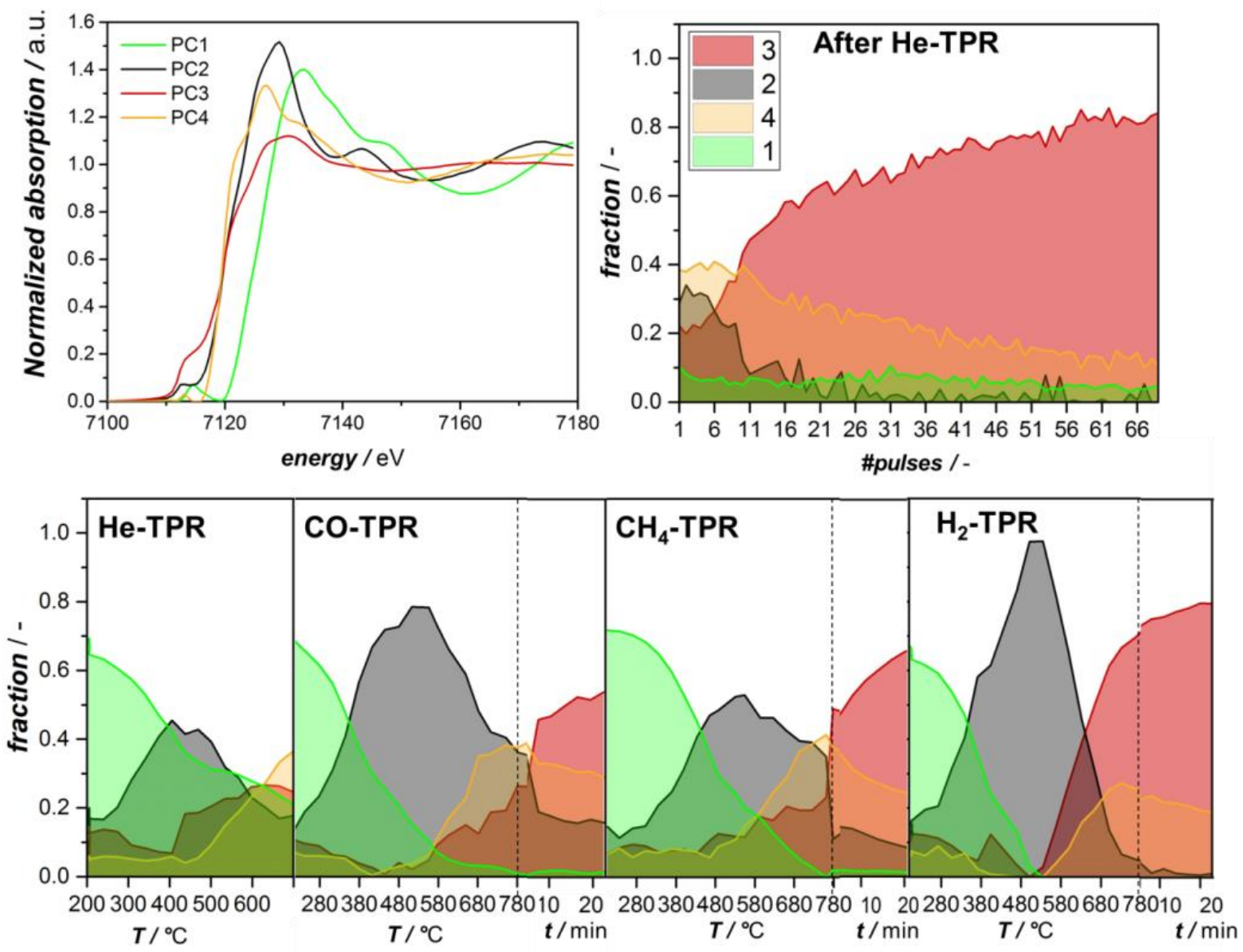

Figure 4. Concentration profiles of the four principal component Fe-species found by MCR-ALS deconvolution of XANES spectra measured during different treatments applied to Fe/HZSM-5. The error bars for the concentration profile are all less than $1 \%$.

The latter assignment is consistent with the resemblance of the FT-EXAFS spectrum taken at the end of MDA reaction with the spectrum of $\mathrm{Fe}_{5} \mathrm{C}_{2}$ and $\mathrm{Fe}_{3} \mathrm{C}$ standards (similar position of the Fe-C and Fe-Fe scattering paths, Figure S16).

After CO-treatment, the MCR-ALS routine still estimates some $\mathrm{FeO}\left(\mathrm{PC}_{2}\right)$ content on the catalyst even during pulsing. This could be indication that some oxygen remains in the lattice of the reduced iron species in the form of $\mathrm{Fe}-\mathrm{O}$ bonds. This is similar to what has been observed for Mo/HZSM- 5 previously, where an (oxy-)carbide was found to be the active phase. 35 This higher contribution of $\mathrm{PC}_{2}$ after CO-treatment coincides to improved catalytic performance after applying the CO-treatment (Figure $\mathbf{S}_{\mathbf{5}}$ ), which could be indication that retaining some lattice oxygen is beneficial for catalytic performance. $\mathrm{PC}_{4}$ is also contained during pulsing after $\mathrm{CO}$ treatment and He-treatment, but less after $\mathrm{H}_{2}$-treatment and completely vanishes on Fe/HZSM-5,b2 (Figure S24).

This correlates with catalytic activity as benzene production is highest after CO-treatment, followed by He-treatment, then $\mathrm{H}_{2}$-treatment and finally Fe/HZSM-5, b2 that contains bigger particles of Fe.

\subsection{Structural differences between Fe/HZSM-5 and Mo/HZSM-5}

Even after applying the CO-treatment to Fe/HZSM-5, methane conversion levels and yields to naphthalene and benzene do not reach those observed with Mo/HZSM-5. As indicated by the analysis of operando XANES spectra and the differences in carburizability, Fe forms bigger clusters on HZSM-5 ( $c f$. FT-EXAFS in Figure S27) and also carburizes to a lesser extent. For Mo it was found that the carbidic carbon crucially affects catalytic behavior. The initial methane conversion level linearly increases with the amount of carbidic carbon present at the active site, the carbon from the active site is incorporated into the final products and a catalyst merely reduced in $\mathrm{H}_{2}$ without the formation of carbidic carbon is not immediately active to transform methane into aromatics. ${ }^{6}$ Similarly, Fe/HZSM-5 reduced in $\mathrm{H}_{2}$ is not immediately active to form aromatics (Figure S28). A catalyst activated in $\mathrm{CO}$ however is active right after the treatment (Figure S9). A possible explanation is that although the XANES spectrum measured after $\mathrm{H}_{2}$-reduction looks very similar to a spectrum measured after activation in methane (Figure S29), no carbidic carbon was incorporated at the active site during this treatment. The presence of carbidic carbon was also found to stabilize the Fe clusters. 


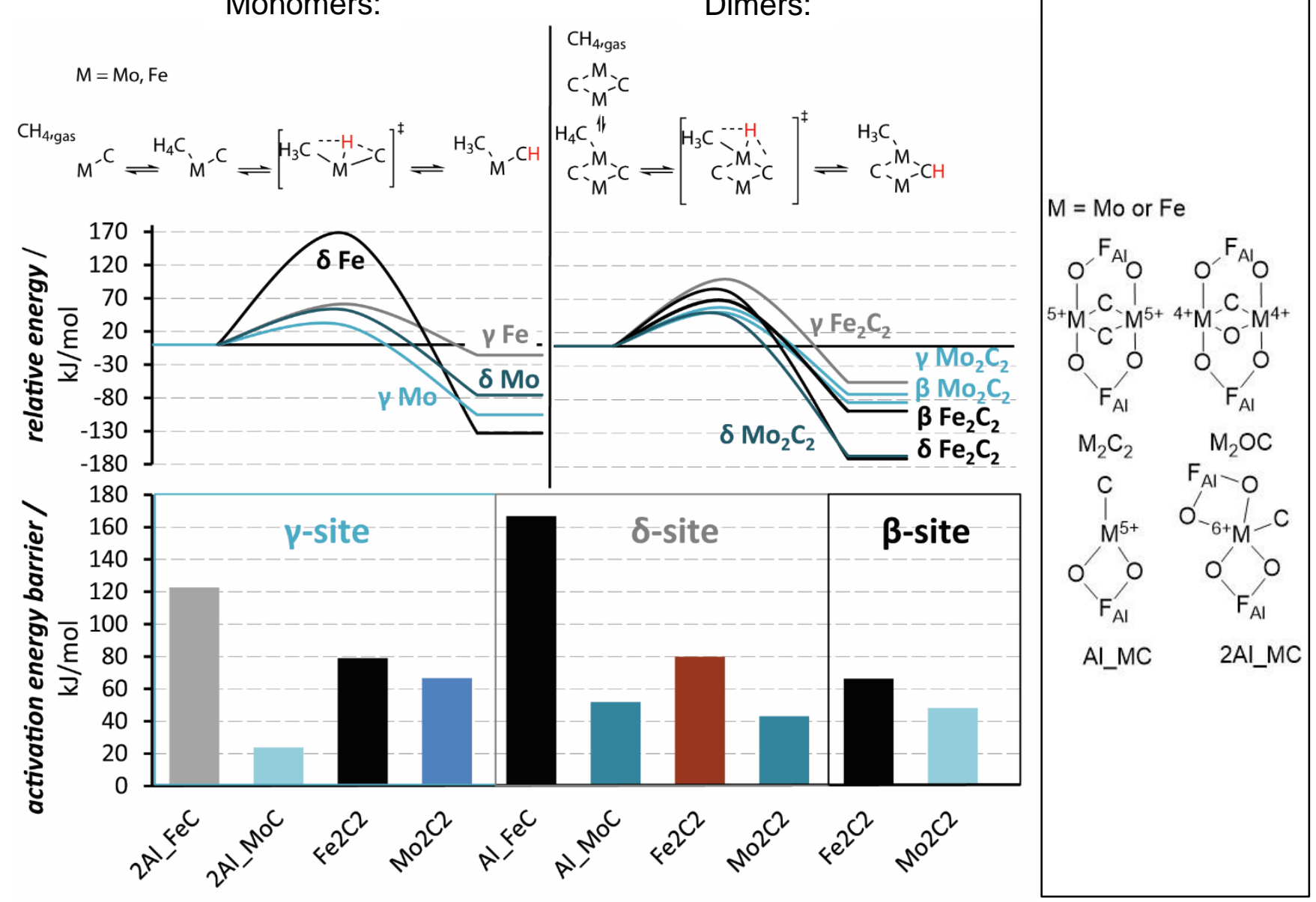

Figure 5. Selection of activation energy barriers calculated for breaking the $\mathrm{C}-\mathrm{H}$ bond in methane over both Fe and Mo structures. Monomers and dimers were considered (insert on the right, $\mathrm{F}_{\mathrm{Al}}=$ framework $\left.\mathrm{Al}\right)$. For the dimers, both carbides $\left(\mathrm{M}_{2} \mathrm{C}_{2}\right)$ and (oxy-)carbidic $\left(\mathrm{M}_{2} \mathrm{OC}\right.$, see Figure $\left.S_{36}\right)$ structures were considered. The $\delta$ - , $\beta$ - and $\gamma$-site were considered as possible locations for the structures in the ZSM-5 framework (Figure S34). Energy is presented relative to initial state of methane approaching the active site. The top shows the pathway considered for the methane $\mathrm{C}-\mathrm{H}$ bond breaking.

The EXAFS spectrum measured after the $\mathrm{H}_{2}$ treatment displays an enhanced Fe-Fe scattering indicating the agglomeration of Fe clusters to bigger nanoparticles (Figure $S_{30}$ ). When this catalyst is subjected to methane again after the treatment, the long range order decreases again, indicating that the carburizing $\mathrm{CH}_{4}$ atmosphere essentially breaks up the Fe nanoparticles. This is due to carbon nanotube formation as revealed by TEM images taken on the spent samples (Figure S21).Apart from the differences in the structure of the activated catalysts, already the as-synthesized Fe/HZSM-5 shows a larger amount of bigger TM clusters compared to the as-synthesized Mo/HZSM-5. Py-IR showed that less acid sites are covered when introducing $\mathrm{Fe}$ to HZSM-5 than when doing the same with Mo (Figure S18). This means that less Fe is anchored to the framework $\mathrm{Al}$ and consequently bigger clusters of Fe are formed on the outer surface of the zeolite crystal. Other synthesis techniques, such as chemical vapor deposition (CVD) ${ }^{23}$ and solid ion exchange (SIE $)^{26}$ were reported to lead to a better dispersion of Fe, but catalysts synthesized using CVD were only active after an additional water treatment and both synthesis methods yielded catalysts underperforming the one synthesized using the more widely used IWI (Figure S31-32). This confirms earlier findings. ${ }^{17}$
The structural differences of Fe compared to Mo partly explain the catalytic behavior. TM nanoparticles and big clusters on the outer surface of the zeolite crystal are responsible for enhanced coking. ${ }^{31}, 35$ This can also be seen from the carbon nanotube formation observed by TEM measurements on the spent catalyst (Figure S21). To test how the size of the Fe species affects catalytic performance, two slightly different IWI methods were used to introduce Fe to HZSM-5 (see section S9). EXAFS measurements on the as-synthesized samples confirm that batch 2 has a higher long-range order than batch 1 (Figure S27). Indeed, the bigger particle size catalyst gives lower yields of benzene and naphthalene as well as a lower methane conversion (Figure S26). Also the activation period takes longer for batch 2 than for batch 1 .

\subsection{Theoretical calculations of activation energy barri- ers}

Higher dispersion of the TM, decreasing the number and size of nanoparticles as well as a pre-carburization treatment present optimization options for the Fe/HZSM-5 catalyst. Theoretical calculations were performed to assess whether a fully optimized catalyst could theoretically reach the performance of Mo/HZSM-5. Oxidic, (oxy-)carbidic and fully carbidic and metal structures of each Fe and Mo were considered as active sites. Mono- and dimeric structures anchored 
to the framework $\mathrm{Al}$ of the zeolite located at the $\gamma^{-}, \delta$ - and $\beta$ site of the framework (right insert Figure 5, Figure S33-35) were considered. It has been shown that mono- and dimeric Mo structures are most dominant, ${ }^{14}$ and active ${ }^{16}$ on HZSM- 5 and that under reaction atmosphere the (oxy-)carbidic Mo structures considered were thermodynamically most stable. 49 To create a fair comparison, structurally equivalent structures of Fe were used. As the presence of nanoparticles of Fe and Mo cannot be excluded, activation of methane was also studied on the most stable carbidic ${ }^{52-53}$ and metallic surfaces of Fe as well as on the most stable $\beta-\mathrm{Mo}_{2} \mathrm{C}$ (lo 11 ) surface ${ }^{54,} 74$ (Figure S37). The activation energy barriers for the methane $\mathrm{C}$ - $\mathrm{H}$ bond breaking were calculated as this step is deemed to be rate-determining for MDA.75

The activation energy barriers are consistently lower over Mo structures than over Fe structures (Figure 5), which explains the lower methane conversion and aromatic yields observed over Fe/HZSM-5. The top of Figure 5 shows a scheme of the reaction trajectory and transition state (TS) of $\mathrm{C}-\mathrm{H}$ bond dissociation. The geometry of the TSs observed on all Mo structures and on Fe dimers is similar to what was observed earlier for Mo tetramers (Table S8). 47 For Fe monomers, however, the geometry of the TS is different in that the $\mathrm{CH}_{3}$ fragment does not interact with Fe. Also, in the final state, $\mathrm{CH}_{3}$ is not absorbed on Fe but attaches to the carbidic carbon (Scheme 2). This explains the large difference in activation energy barriers observed for Fe and Mo monomers. The limited interaction between $\mathrm{Fe}$ and methane is likely due to a strong stabilization of the Fe by bonding to the electron-withdrawing zeolite framework, evident from the shorter distance between Fe and bridging oxygen, which is between 0.1 and $0.2 \AA$ shorter. Fe monomers become more active, when the interaction with the framework is weakened and less electrons are donated to the framework as is the case for monomers anchored to only one $\mathrm{F}_{\mathrm{Al}}$ or for Fe dimers. For $\mathrm{FeC}$ anchored to only one $\mathrm{Al}$ in the $\beta$-site, the geometry of the TS becomes similar to the TSs observed over Mo monomers (Figure $\mathbf{S}_{34}$, Scheme 2) and the $\mathrm{CH}_{3}$ fragment is adsorbed on Fe, lowering the activation energy barrier. However, the activation energy barrier on this site is also influenced by the strong VdW interaction due to the confinement

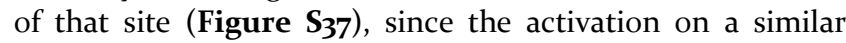
structure located in the $\delta$-site did lower the activation energy barrier. Similarly, for Mo monomers in the $\delta$-site, the $\mathrm{CH}_{3}$ fragment also does not interact with Mo in the TS leading to higher activation energy barriers.

Scheme 2. Pathway of methane $\mathrm{C}-\mathrm{H}$ bond activation over Mo monomers compared to Fe monomers anchored to HZSM-5.

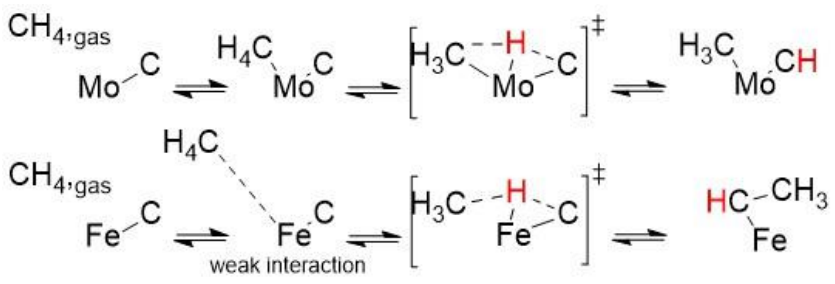

Lower activation energy barriers than reported for Mo tetramers $\left(97.5 \mathrm{~kJ} / \mathrm{mol}\right.$ for $\mathrm{Mo}_{4} \mathrm{C}_{2}{ }^{47}$ ) were observed over both mono- and dimeric Mo structures, suggesting that monoand dimeric Mo structures are the dominant active sites. Next to fully carbidic structures, oxycarbidic dimers were also considered. Activation barriers towards H-adsorption on carbon were higher than over the fully carbidic dimers, while activation with $\mathrm{H}$-adsorption on oxygen of the (oxy-)carbidic dimer is more favorable for Mo, but leads to much higher activation energy barriers for Fe (Figure S36).

Although the methane $\mathrm{C}-\mathrm{H}$ bond breaking and $\mathrm{C}-\mathrm{C}$ coupling were found to easily occur on Mo carbide surfaces, ${ }^{76}$ these structures were also found to be responsible for coke formation. 35 The activation energy barriers calculated over $\mathrm{Fe}_{3} \mathrm{C}, \mathrm{Fe}_{2} \mathrm{C}_{5}$ and $\mathrm{Mo}_{2} \mathrm{C}$ are lower than over the mono- and dimeric structures anchored to the zeolite framework (Figure S36). This does not mean that these nanoparticles are necessarily good catalytic sites for methane aromatization. The low activation barriers and non-isolated nature of the active sites on the nanoparticles likely favor coking. The carbon nanotube formation observed by STEM on the spent catalyst (Figure S21) supports this. Interestingly, very high activation energy barriers were calculated over both metallic $\gamma$-Fe and $\alpha$-Fe structures again explaining, why activation in hydrogen does not lead to an active catalyst and stressing the necessity of carburization. The $\mathrm{Fe}_{2} \mathrm{C}_{5}$ surface presented slightly more active sites for $\mathrm{C}-\mathrm{H}$ bond breaking than the $\mathrm{Fe}_{3} \mathrm{C}$ surface, suggesting that one should try to find an activation treatment that favors $\mathrm{Fe}_{2} \mathrm{C}_{5}$ over $\mathrm{Fe}_{3} \mathrm{C}$.

Comparing the stability (based on relative energy) of carbidic structures located at the three different sites of the zeolite framework, the monomers are most stable at the $\delta$ site 49 (Table S9). This is due to the high symmetry of that site. 49 Dimers are most stable at the $\beta$-site Structures located at the $\gamma$-site are the least stable despite the Van-der-Waals correction being the highest for that site (Figure S37). For the dimers, the most stable structures are also the most active, while no trend could be observed for the monomers.

During the activation period, fully carbidic, oxy-carbidic and metallic phases (for Fe) are formed, as is shown by our characterization. The theoretical results suggest that (oxy)carbidic structures can be active sites, but that a metallic surface is rather inactive for methane $\mathrm{C}-\mathrm{H}$ activation.

\section{Conclusion}

Differences in the catalytic behavior between Fe/HZSM-5 and $\mathrm{Mo}_{\mathrm{HZSM}}-5$ for the methane dehydroaromatization are explained based on structural analysis of the as-synthesized and of the catalyst at reaction conditions using operando $\mathrm{XAS}$, temperature programmed reaction techniques, TEM and Py-IR.

Combining an analysis of the catalytic behavior of the transition metals Fe and Mo supported on HZSM- 5 with operando XAS and other structural characterization is a powerful strategy to infer important parameters determining the catalytic activity of metal-zeolites systems for the methane dehydroaromatization process.

The following trends are inferred from this study. (i) the longer the activation period takes, the lower the methane conversion and the yields to naphthalene and benzene will be because of the accumulation of coke concurrent with carburization. Thus, carburizability of the active metal determines catalytic activity, because (ii) (oxy-)carbidic structures constitute the active phase, while metal surfaces are rather inert to methane $\mathrm{C}-\mathrm{H}$ activation. (iii) One should aim for a catalyst with active sites well separated from one anoth- 
er, ideally as monomers for Mo and dimers for Fe. Bigger particles lead to coking, because of extremely low activation energy barriers and polycondensation reactions occurring at the surface. (iv) CO treatment can not only eliminate the activation period, but also leads to an improved performance of Fe/HZSM-5.

In addition, Mo is inherently more active in abstracting $\mathrm{H}$ from methane as shown by theoretical calculations. Although some possibilities for improvement of the Fe/HZSM- 5 system exist, Fe/HZSM-5 can likely never outperform Mo/HZSM-5 as MDA catalyst in terms of activity.

\section{ASSOCIATED CONTENT}

\section{Supporting Information}

ICP analysis, Catalytic results, Thermodynamics of reduction of bulk oxides, Operando XANES measurements, Pyridine infrared spectroscopy, Experimental method and additional STEM images, Procedure for the singular value decomposition, Alternative synthesis methods with catalytic results, Description of structural models used for theoretical calculations, $\mathrm{N}_{2}$ adsorption and XRD characterization of catalyst The Supporting Information is available free of charge on the ACS Publications website. (file type PDF)

\section{AUTHOR INFORMATION}

\section{Corresponding Author}

Jorge Gascon, Email address:

jorge.gascon@kaust.edu.sa

\section{Present Addresses}

Ina Vollmer, Inorganic Chemistry and Catalysis, Utrecht University, The Netherlands

\section{Author Contributions}

\section{Notes}

The authors declare no competing financial interests.

\section{ACKNOWLEDGMENT}

Financial support from the SABIC-NWO CATC1CHEM CHIPP project (grant $\mathrm{nr}$. 501100003246) is gratefully acknowledged. Thanks go to Dr. Christoph Dittrich (SABIC), Dr. Frank Mostert (SABIC), Dr. T. Alexander Nijhuis (SABIC) for helpful discussion. Dr. María José Valero-Romero (Universidad de Málaga) is also acknowledged for helpful discussion. NWO surfsara is acknowledged for providing access to the supercomputer facilities. Guanna $\mathrm{Li}$ acknowledges financial support from the NWO veni grant (no.o16.Veni.172.034).

\section{ABBREVIATIONS}

MDA, Methane dehydroaromatizationi; XANES, X-ray absorption near-edge spectroscopy; TS, transition state.

\section{REFERENCES}

1. Schwach, P.; Pan, X.; Bao, X., Direct Conversion of Methane to Value-Added Chemicals over Heterogeneous Catalysts: Challenges and Prospects. Chemical Reviews 2017, 117 (13), 8497-8520.
2. Laboratory, N. E. T., An introduction to the science and energy potential of a unique resource. Energy, U. D. o., Ed. US Department of Energy: US, 2011.

3. Weckhuysen, B. M.; Wang, D.; Rosynek, M. P.; Lunsford, J. H., Conversion of Methane to Benzene over Transition Metal Ion ZSM-5 Zeolites. Journal of Catalysis 1998, 175 (2), 338-346.

4. $\quad$ Wang, L.; Ohnishi, R.; Ichikawa, M., Selective Dehydroaromatization of Methane toward Benzene on Re/HZSM-5 Catalysts and Effects of $\mathrm{CO} / \mathrm{CO}_{2}$ Addition. Journal of Catalysis 2ooo, 190 (2), 276-283.

5. Gabrienko, A. A.; Arzumanov, S. S.; Moroz, I. B.; Toktarev, A. V.; Wang, W.; Stepanov, A. G., Methane Activation and Transformation on Ag/H-ZSM-5 Zeolite Studied with Solid-State NMR. The Journal of Physical Chemistry C 2013, 117 (15), 7690-7702. 6. Baba, T.; Sawada, H., Conversion of methane into higher hydrocarbons in the presence of ethylene over H-ZSM-5 loaded with silver cations. Physical Chemistry Chemical Physics 2002, 4 (15), 39193923.

7. Baba, T.; Abe, Y., Metal cation-acidic proton bifunctional catalyst for methane activation: conversion of ${ }_{13} \mathrm{CH}_{4}$ in the presence of ethylene over metal cations-loaded H-ZSM-5. Applied Catalysis A: General 2003, 250 (2), 265-270.

$8 . \quad$ Liu, B. S.; Zhang, Y.; Liu, J. F.; Tian, M.; Zhang, F. M.; Au, C. T.; Cheung, A. S. C., Characteristic and Mechanism of Methane Dehydroaromatization over Zn-Based/HZSM-5 Catalysts under Conditions of Atmospheric Pressure and Supersonic Jet Expansion. The Journal of Physical Chemistry C 2011, 115 (34), 16954-16962. 9. $\quad$ Abdelsayed, V.; Smith, M. W.; Shekhawat, D., Investigation of the stability of Zn-based HZSM- 5 catalysts for methane dehydroaromatization. Applied Catalysis A: General 2015, 505, 365-374.

10. Kazansky, V. B.; Serykh, A. I.; Pidko, E. A., DRIFT study of molecular and dissociative adsorption of light paraffins by HZSM- 5 zeolite modified with zinc ions: methane adsorption. Journal of Catalysis 2004, 225 (2), 369-373.

11. Q Qi, G.; Wang, Q.; Xu, J.; Trébosc, J.; Lafon, O.; Wang, C.; Amoureux, J. P.; Deng, F., Synergic Effect of Active Sites in ZincModified ZSM-5 Zeolites as Revealed by High-Field Solid-State NMR Spectroscopy. Angewandte Chemie 2016, 55 (51), 15826-15830.

12. Gabrienko, A. A.; Arzumanov, S. S.; Moroz, I. B.; Prosvirin, I. P.; Toktarev, A. V.; Wang, W.; Stepanov, A. G., Methane Activation on In-Modified ZSM-5: The State of Indium in the Zeolite and

Pathways of Methane Transformation to Surface Species. The Journal of Physical Chemistry C 2014, 118 (15), 8034-8043.

13. Ding, W.; Meitzner, G. D.; Marler, D. O.; Iglesia, E., Synthesis, Structural Characterization, and Catalytic Properties of Tungsten-Exchanged H-ZSM5. The Journal of Physical Chemistry $B$ 2001, 105 (18), 3928-3936.

14. Gao, J.; Zheng, Y.; Jehng, J.-M.; Tang, Y.; Wachs, I. E.; Podkolzin, S. G., Identification of molybdenum oxide nanostructures on zeolites for natural gas conversion. Science 2015, 348 (6235), 686690.

15. Kosinov, N.; Coumans, F. J.; Li, G.; Uslamin, E.; Mezari, B.; Wijpkema, A. S.; Pidko, E. A.; Hensen, E. J., Stable Mo/HZSM-5 methane dehydroaromatization catalysts optimized for hightemperature calcination-regeneration. Journal of Catalysis 2017, 346, 125-133.

16. Vollmer, I.; Mondal, A.; Yarulina, I.; Abou-Hamad, E.; Kapteijn, F.; Gascon, J., Quantifying the impact of dispersion, acidity and porosity of Mo/HZSM- 5 on the performance in methane dehydroaromatization. Applied Catalysis A: General 2019, 574, 144150 .

17. Weckhuysen, B. M.; Wang, D.; Rosynek, M. P.; Lunsford, J. H., Catalytic Conversion of Methane into Aromatic Hydrocarbons over Iron Oxide Loaded ZSM-5 Zeolites. Angewandte Chemie International Edition in English 1997, 36 (21), 2374-2376.

18. Battiston, A. A.; Bitter, J. H.; de Groot, F. M. F.; Overweg, A. R.; Stephan, O.; van Bokhoven, J. A.; Kooyman, P. J.; van der Spek, C.; Vankó, G.; Koningsberger, D. C., Evolution of Fe species during the synthesis of over-exchanged Fe/ZSM 5 obtained by chemical vapor deposition of $\mathrm{FeCl}_{3}$. Journal of Catalysis 2003, 213 (2), 251-271. 
19. Boubnov, A.; Carvalho, H. W. P.; Doronkin, D. E.; Günter, T.; Gallo, E.; Atkins, A. J.; Jacob, C. R.; Grunwaldt, J.-D., Selective Catalytic Reduction of NO Over Fe-ZSM-5: Mechanistic Insights by Operando HERFD-XANES and Valence-to-Core X-ray Emission Spectroscopy. Journal of the American Chemical Society 2014, 136 (37), 13006-13015.

20. Chen, H.-Y.; Sachtler, W. M. H., Promoted Fe/ZSM-5 catalysts prepared by sublimation: de-NOx activity and durability in $\mathrm{H}_{2} \mathrm{O}$-rich streams. Catal Lett 1998, 50 (3), 125-130.

21. Chen, H.-Y.; Sachtler, W. M. H., Activity and durability of Fe/ZSM-5 catalysts for lean burn NOx reduction in the presence of water vapor. Catalysis Today 1998, 42 (1), 73-83.

22. Dubkov, K. A.; Ovanesyan, N. S.; Shteinman, A. A.;

Starokon, E. V.; Panov, G. I., Evolution of Iron States and Formation of $\alpha$-Sites upon Activation of FeZSM-5 Zeolites. Journal of Catalysis 2002, 207 (2), 341-352.

23. El-Malki, E.-M.; van Santen, R. A.; Sachtler, W. M. H., Active Sites in Fe/MFI Catalysts for NOx Reduction and Oscillating $\mathrm{N}_{2} \mathrm{O}$ Decomposition. Journal of Catalysis 2000, 196 (2), 212-223.

24. Heinrich, F.; Schmidt, C.; Löffler, E.; Menzel, M.; Grünert, W., Fe-ZSM- 5 Catalysts for the Selective Reduction of NO by Isobutane-The Problem of the Active Sites. Journal of Catalysis 2002, 212 (2), 157-172.

25. Lai, S.; She, Y.; Zhan, W.; Guo, Y.; Guo, Y.; Wang, L.; Lu, G., Performance of Fe-ZSM- 5 for selective catalytic reduction of NOx with $\mathrm{NH}_{3}$ : Effect of the atmosphere during the preparation of catalysts. Journal of Molecular Catalysis A: Chemical 2016, 424, 232240.

26. Lobree, L. J.; Hwang, I.-C.; Reimer, J. A.; Bell, A. T., Investigations of the State of Fe in H-ZSM-5. Journal of Catalysis 1999, 186 (2), 242-253.

27. $\quad$ Pirngruber, G. D.; Grunwaldt, J.-D.; Roy, P. K.; van Bokhoven, J. A.; Safonova, O.; Glatzel, P., The nature of the active site in the Fe-ZSM-5/N2O system studied by (resonant) inelastic Xray scattering. Catalysis Today 2007, 126 (1), 127-134.

28. Sazama, P.; Wichterlová, B.; Tábor, E.; Štastný, P.; Sathu, N. K.; Sobalík, Z.; Dědeček, J.; Sklenák, Š.; Klein, P.; Vondrová, A., Tailoring of the structure of Fe-cationic species in Fe-ZSM- 5 by distribution of $\mathrm{Al}$ atoms in the framework for $\mathrm{N}_{2} \mathrm{O}$ decomposition and NH3-SCR-NOx. Journal of Catalysis 2014, 312, 123-138.

29. Snyder, B. E. R.; Bols, M. L.; Schoonheydt, R. A.; Sels, B. F.; Solomon, E. I., Iron and Copper Active Sites in Zeolites and Their Correlation to Metalloenzymes. Chemical Reviews 2018, 118 (5), 27182768 .

3o. El-Malki, E.-M.; van Santen, R. A.; Sachtler, W. M. H., Introduction of Zn, Ga, and Fe into HZSM-5 Cavities by Sublimation: Identification of Acid Sites. The Journal of Physical Chemistry B 1999, 103 (22), 4611-4622.

31. Lai, Y.; Veser, G., The nature of the selective species in FeHZSM- 5 for non-oxidative methane dehydroaromatization. Catalysis Science \& Technology 2016, 6 (14), 5440-5452.

32. Tan, P., Active phase, catalytic activity, and induction period of $\mathrm{Fe} /$ zeolite material in nonoxidative aromatization of methane. Journal of Catalysis 2016, 338, 21-29.

33. Ma, D.; Shu, Y.; Cheng, M.; Xu, Y.; Bao, X., On the Induction Period of Methane Aromatization over Mo-Based Catalysts. Journal of Catalysis 200o, 194 (1), 105-114.

34. Kosinov, N.; Wijpkema, A. S. G.; Uslamin, E.; Rohling, R.; Coumans, F. J. A. G.; Mezari, B.; Parastaev, A.; Poryvaev, A. S.; Fedin, M. V.; Pidko, E. A.; Hensen, E. J. M., Confined Carbon Mediating Dehydroaromatization of Methane over Mo/ZSM-5. Angewandte Chemie 2018, 57 (4), 1016-1020.

35. Vollmer, I.; Kosinov, N.; Szécsényi, Á.; Li, G.; Yarulina, I.; Abou-Hamad, E.; Gurinov, A.; Ould-Chikh, S.; Aguilar-Tapia, A.; Hazemann, J.-L.; Pidko, E.; Hensen, E.; Kapteijn, F.; Gascon, J., A site-sensitive quasi-in situ strategy to characterize Mo/HZSM-5 during activation. Journal of Catalysis 2019, 370, 321-331.

36. Vollmer, I.; van der Linden, B.; Ould-Chikh, S.; AguilarTapia, A.; Yarulina, I.; Abou-Hamad, E.; Sneider, Y. G.; Olivos Suarez, A. I.; Hazemann, J.-L.; Kapteijn, F.; Gascon, J., On the dynamic nature of Mo sites for methane dehydroaromatization. Chemical Science 2018, 9 (21), 4801-4807.

37. Doornkamp, C.; Ponec, V., The universal character of the Mars and Van Krevelen mechanism. Journal of Molecular Catalysis A: Chemical 200o, 162 (1), 19-32.

38. Santos, V. P.; Wezendonk, T. A.; Jaén, J. J. D.; Dugulan, A. I.; Nasalevich, M. A.; Islam, H.-U.; Chojecki, A.; Sartipi, S.; Sun, X.; Hakeem, A. A.; Koeken, A. C. J.; Ruitenbeek, M.; Davidian, T.; Meima, G. R.; Sankar, G.; Kapteijn, F.; Makkee, M.; Gascon, J., Metal organic framework-mediated synthesis of highly active and stable Fischer-Tropsch catalysts. Nat Commun 2015, 6.

39. Xu, K.; Sun, B.; Lin, J.; Wen, W.; Pei, Y.; Yan, S.; Qiao, M.; Zhang, X.; Zong, B., $\varepsilon$-Iron carbide as a low-temperature FischerTropsch synthesis catalyst. 2014, 5, 5783 .

4o. Ordomsky, V. V.; Legras, B.; Cheng, K.; Paul, S.; Khodakov, A. Y., The role of carbon atoms of supported iron carbides in FischerTropsch synthesis. Catalysis Science E Technology 2015, 5 (3), 14331437.

41. Lezcano-González, I.; Oord, R.; Rovezzi, M.; Glatzel, P.; Botchway, S. W.; Weckhuysen, B. M.; Beale, A. M., Molybdenum Speciation and its Impact on Catalytic Activity during Methane Dehydroaromatization in Zeolite ZSM- 5 as Revealed by Operando XRay Methods. Angewandte Chemie International Edition 2016, 55, 5215-5219.

42. Liu, B. S.; Jiang, L.; Sun, H.; Au, C. T., XPS, XAES, and TG/DTA characterization of deposited carbon in methane dehydroaromatization over Ga-Mo/ZSM-5 catalyst. Applied Surface Science 2007, 253 (11), 5092-5100.

43. Agote-Arán, M.; Kroner, A. B.; Islam, H. U.; Sławiński, W. A.; Wragg, D. S.; Lezcano-González, I.; Beale, A. M., Determination of Molybdenum Species Evolution during Non-Oxidative Dehydroaromatization of Methane and its Implications for Catalytic Performance. ChemCatChem 11 (1), 473-480.

44. Pappas, D. K.; Martini, A.; Dyballa, M.; Kvande, K.;

Teketel, S.; Lomachenko, K. A.; Baran, R.; Glatzel, P.; Arstad, B.;

Berlier, G.; Lamberti, C.; Bordiga, S.; Olsbye, U.; Svelle, S.; Beato, P.; Borfecchia, E., The Nuclearity of the Active Site for Methane to Methanol Conversion in Cu-Mordenite: A Quantitative Assessment. Journal of the American Chemical Society 2018, 140 (45), 15270-15278. 45. Jaumot, J.; Gargallo, R.; de Juan, A.; Tauler, R., A graphical user-friendly interface for MCR-ALS: a new tool for multivariate curve resolution in MATLAB. Chemometrics and Intelligent Laboratory Systems 2005, 76 (1), 101-110.

46. Martini, A.; Borfecchia, E.; Lomachenko, K. A.; Pankin, I. A.; Negri, C.; Berlier, G.; Beato, P.; Falsig, H.; Bordiga, S.; Lamberti, C., Composition-driven $\mathrm{Cu}$-speciation and reducibility in $\mathrm{Cu}-\mathrm{CHA}$ zeolite catalysts: a multivariate XAS/FTIR approach to complexity. Chemical Science 2017, 8 (10), 6836-6851.

47. Yin, F.; Wang, G.; Li, M.-R., A Periodic Density Functional Theory Analysis of Direct Methane Conversion into Ethylene and Aromatic Hydrocarbons Catalyzed by Mo4C2/ZSM-5. Physical Chemistry Chemical Physics 2017, 19 (33), 22243-22255.

48. Jaumot, J.; de Juan, A.; Tauler, R., MCR-ALS GUI 2.o: New features and applications. Chemometrics and Intelligent Laboratory Systems 2015, 140, 1-12.

49. Li, G.; Pidko, E. A.; van Santen, R. A.; Li, C.; Hensen, E. J. M., Stability of Extraframework Iron-Containing Complexes in ZSM5 Zeolite. The Journal of Physical Chemistry C 2013, 117 (1), 413-426. 50. Dedecek, J.; Balgová, V.; Pashkova, V.; Klein, P.; Wichterlová, B., Synthesis of ZSM-5 Zeolites with Defined Distribution of Al Atoms in the Framework and Multinuclear MAS NMR Analysis of the Control of Al Distribution. Chemistry of Materials 2012, 24 (16), 3231-3239. 51. Vollmer, I.; Li, G.; Yarulina, I.; Kosinov, N.; Hensen, E. J.; Houben, K.; Mance, D.; Baldus, M.; Gascon, J.; Kapteijn, F., Relevance of the Mo-precursor state in $\mathrm{H}_{-\mathrm{ZSM}}-5$ for methane dehydroaromatization. Catalysis Science \& Technology 2018, 8 (3), 916-922.

52. $\quad$ Steynberg, P.; Van den Berg, J.; van Rensburg, W. J., Bulk and surface analysis of Hägg Fe carbide $\left(\mathrm{Fe}_{5} \mathrm{C}_{2}\right)$ : a density functional 
theory study. Journal of Physics: Condensed Matter 2008, 20 (6), 064238 .

53. Chiou, W. C.; Carter, E. A., Structure and stability of $\mathrm{Fe}_{3} \mathrm{C}-$ cementite surfaces from first principles. Surface Science 2003, 530 (1), 88-100.

54. dos Santos Politi, J. R.; Viñes, F.; Rodriguez, J. A.; Illas, F., Atomic and electronic structure of molybdenum carbide phases: bulk and low Miller-index surfaces. Physical Chemistry Chemical Physics 2013, 15 (30), 12617-12625.

55. Shi, X.-R.; Wang, S.-G.; Wang, H.; Deng, C.-M.; Qin, Z.; Wang, J., Structure and stability of $\beta$-Mo2C bulk and surfaces: A density functional theory study. Surface Science 2009, 603 (6), 852859 .

56. Kresse, G.; Hafner, J., Ab initio molecular dynamics for liquid metals. Physical Review B 1993, 47 (1), 558-561.

57. $\quad$ Kresse, G.; Hafner, J., Ab initio molecular-dynamics simulation of the liquid-metal-amorphous-semiconductor transition in germanium. Physical Review B 1994, 49 14251-14269.

58. Kresse, G.; Furthmüller, J., Efficient iterative schemes for ab initio total-energy calculations using a plane-wave basis set. Physical Review B 1996, 54 (16), 11169-11186.

59. Kresse, G.; Furthmüller, J., Efficiency of ab-initio total energy calculations for metals and semiconductors using a planewave basis set. Computational Materials Science 1996, 6 (1), 15-50. 6o. $\quad$ Perdew, J. P.; Burke, K.; Ernzerhof, M., Generalized Gradient Approximation Made Simple. Physical Review Letters 1996, 77 (18), 3865-3868.

61. Blöchl, P. E., Projector augmented-wave method. Physical Review B 1994, 50 (24), 17953-17979.

62. Kresse, G.; Joubert, D., From ultrasoft pseudopotentials to the projector augmented-wave method. Physical Review B 1999, 59 (3), 1758-1775.

63. Monkhorst, H. J.; Pack, J. D., Special points for Brillouinzone integrations. Physical Review B 1976, 13 (12), 5188-5192.

64. Grimme, S., S. Grimme, J. Antony, S. Ehrlich, and H. Krieg, A consistent and accurate $\mathrm{ab}$ initio parametrization of density functional dispersion correction (DFT-D) for the 94 elements $\mathrm{H}-\mathrm{Pu}$, J. Chem. Phys. 132, 154104 (2010). J. Chem. Phys. 2010, 132, 154104. 65. Henkelman, G.; Uberuaga, B. P.; Jónsson, H., A climbing image nudged elastic band method for finding saddle points and minimum energy paths. The Journal of Chemical Physics 200o, 113 (22), 9901-9904.
66. Denardin, F.; Perez-Lopez, O. W., Tuning the acidity and reducibility of $\mathrm{Fe} / \mathrm{ZSM}-5$ catalysts for methane

dehydroaromatization. Fuel 2019, 236, 1293-1300.

67. Vollmer, I.; Yarulina, I.; Kapteijn, F.; Gascon, J., Progress in Developing a Structure-Activity Relationship for the Direct Aromatization of Methane. ChemCatChem 2019, 11 (1), 39-52. 68. Jiang, H.; Wang, L.; Cui, W.; Xu, Y., Study on the induction period of methane aromatization over Mo/HZSM-5: partial reduction of Mo species and formation of carbonaceous deposit. Catal Lett 1999, 57 (3), 95-102.

69. Solymosi, F.; Szöke, A.; Cserényi, J., Conversion of methane to benzene over Mo2 $\mathrm{C}$ and $\mathrm{Moz}_{2} \mathrm{C} / \mathrm{ZSM}-5$ catalysts. Catal Lett 1996, 39 (3-4), 157-161.

7o. Wang, D.; Lunsford, J.; Rosynek, M., Catalytic conversion of methane to benzene over Mo/ZSM-5. Top Catal 1996, 3 (3-4), 289297.

71. Liu, S.; Wang, L.; Ohnishi, R.; Lchikawa, M., Bifunctional catalysis of Mo/HZSM- 5 in the dehydroaromatization of methane with $\mathrm{CO} / \mathrm{CO}_{2}$ to benzene and naphthalene. Kinetics and catalysis 200o, 41 (1), 132-144.

72. Ding, W.; Li, S.; D Meitzner, G.; Iglesia, E., Methane conversion to aromatics on $\mathrm{Mo}_{\mathrm{H}} \mathrm{H}-\mathrm{ZSM}_{5}$ : structure of molybdenum species in working catalysts. The Journal of Physical Chemistry $B$ 2001, 105 (2), 506-513.

73. Chen, L. Y.; Lin, L. W.; Xu, Z. S.; Li, X. S.; Zhang, T., Dehydro-oligomerization of Methane to Ethylene and Aromatics over Molybdenum/HZSM-5 Catalyst. Journal of Catalysis 1995, 157 (1), 190-200.

74. Wang, T.; Luo, Q.; Li, Y.-W.; Wang, J.; Beller, M.; Jiao, H., Stable surface terminations of orthorhombic $\mathrm{Moz}_{2} \mathrm{C}$ catalysts and their CO activation mechanisms. Applied Catalysis A: General 2014, 478, 146-156.

75. $\quad$ Zheng, Y.; Tang, Y.; Gallagher, J. R.; Gao, J.; Miller, J. T.; Wachs, I. E.; Podkolzin, S. G., Molybdenum Oxide, Oxycarbide, and Carbide: Controlling the Dynamic Composition, Size, and Catalytic Activity of Zeolite-Supported Nanostructures. The Journal of Physical Chemistry C 2019, 123 (36), 22281-22292.

76. Zhang, T.; Yang, X.; Ge, Q., $\mathrm{CH}_{4}$ dissociation and CC coupling on Mo-terminated MoC surfaces: A DFT study. Catalysis Today 2019, 339, 54-61. 
TOC

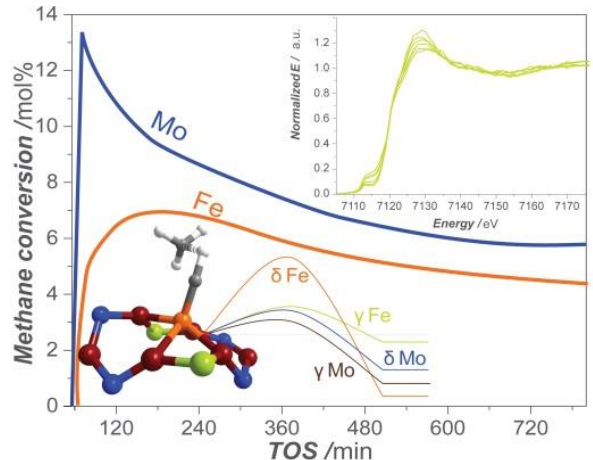

